\title{
COST-BENEFIT ANALYSIS OF CONVERTING AGRICULTURAL LAND INTO SOLAR FARM USING RS \& GIS: CASE OF TARLAC PROVINCE
}

\author{
A.D. de Luna ${ }^{1 *}$, C.E.B. Pascual ${ }^{2}$, J. A. Principe ${ }^{3}$,M.R.C.O. Ang ${ }^{4}$ \\ Department of Geodetic Engineering, University of the Philippines Diliman, Quezon City \\ ${ }^{1}$ addeluna@up.edu.ph, ${ }^{2}$ cbpascual3@up.edu.ph, ${ }^{3}$ japrincipe@ up.edu.ph, ${ }^{4}$ moang@up.edu.ph
}

\begin{abstract}
KEY WORDS: Solar farms, Remote Sensing, Geographic Information Systems, Suitability Map, Rice Yield Estimation
\end{abstract}
\begin{abstract}
:
The Philippines relies heavily on fossil fuels. With its high energy consumption, the country is at risk economically because of possible supply constraints by exporters, and price fluctuations of fossil fuels. One alternative to fossil fuels is solar. This study aims to explore the use of satellite data analytics and Geographic Information System (GIS) in making a granular site suitability assessment for solar photovoltaic (PV) projects in the province of Tarlac and perform a cost-benefit analysis for rice field conversion to solar farms. Remote sensing (RS) and GIS techniques were used to estimate values of factors and constraints to generate a suitability map of solar farm installation in Tarlac considering rice yield. Input data such as Sentinel 2A image tiles and statistical data from databases online were gathered and geospatial analyst processes were done, particularly in assigning weights to the said factors and constraints. For accuracy assessment of image classification, values of kappa coefficient $(k)$ and overall accuracy (OA) were computed. A final suitability map is then applied together with the constraints. This is then compared with existing and upcoming solar farm projects to see if the suitability map can be considered or there is analysis on whether a prime rice field had been converted. Costs, on one hand, such as the forgone net profit from the agricultural land and rice yield loss was presented. The benefits, on the other hand, include the estimated net returns of the solar farm, the amount of energy generated, and the reduced carbon emissions. Different ranges for several of the variables were considered so a more thorough analysis could be presented. Values of $k$ and OA were $62.2 \%$ and $71.27 \%$, respectively, indicating a satisfactory accuracy of image classification. In all instances it was shown that in terms of the costs and benefits considered, agricultural land conversion into solar farms may be beneficial for the province of Tarlac. The study showed that this would match the estimated net profit of rice farm areas selected at around $\mathrm{P} 123 \mathrm{M}$ with $\mathrm{P} 133 \mathrm{M}$, but at best estimated net profits could go as high as around $\mathrm{P} 5 \mathrm{M}$. This study has also emphasized the environmental benefit of converting agricultural areas to solar farms by lowering the province's dependence on non-renewable sources of energy, particularly coal in this case. The approximated reduction in emissions was $33.7 \%$ of the emissions of the whole province. It was also notable how much of the national rice supply could be affected as rice supply for more than 200,000 people for a year would have to be forgone.
\end{abstract}

\section{INTRODUCTION}

\subsection{Background of the Study}

The Philippines' has an energy problem: an over reliance on fossil fuels coupled with high energy consumption. This puts the country at risk economically because of possible supply constraints by exporters, and price fluctuations of fossil fuels. With the government's plan of raising GDP growth to $7 \%$ by 2040 , energy consumption growth is also to be expected (France-Presse, 2011). Moreover,the country's geographical location puts the Philippines at risk of the ill effects of extreme weather events, the intensity and frequency of which are associated by climate change (Mondal, et. al, 2021).

\subsection{Statement of the Problem}

The Philippines is one of the countries in Asia with the highest cost of electricity (France-Presse, 2011). Dela Cruz and Petty (2017) indicated that in the next five years, an anticipated $7 \mathrm{GW}$ of power has to be generated to meet the power requirements of the country. Of 102 million people in the Philippines, 16 million are currently off the grid and have no supply of electricity. Despite the promising potential of solar energy, the Philippines is falling behind its neighboring Asian countries, with regards to deployment and policy implementation (Climate Action, 2017). This emphasizes the need for the exploration of renewable energy sources to provide Filipinos with basic services such as electricity.

\subsection{Significance of the Study}

Solar is a renewable energy source that the Philippines should be highly motivated to tap. This is due to the country's high solar power potential (mainly due to its geographical location), and the presence of local solar PV system providers that have flexible payment schemes (Guno, et. al, 2021).

Even with high solar potential due to its ideal geographical location, the country lags behind its Asian neighbors in terms of utility-scale solar PV installations due to economic and environmental issues (Deutsche Gesellschaft für Internationale Zusammenarbeit, 2013). Meanwhile, solar energy provides greater access to energy supplies to off-grid areas and these have to be strategically placed. Locating suitable areas for solar farms has been done by numerous studies including Sola, et. al's (2019) study on selection of 
optimal solar farms in Pampanga which used Remote sensing and Geographic Information System (GIS).

Rice is one of the most important agricultural crops for food security and plays a role in the economy. This is particularly true for a predominantly agricultural country like the Philippines and whose people consider rice as a staple food. Estimation of rice yield is therefore crucial for the country in preparation for extreme weather conditions.

This study is significant to farmers who will be given an option to give up rice farms in favor of solar farms or retain the current use of their agricultural lands especially to those under the rice industry.

\subsection{Objective}

The study aims to explore the use of satellite remote sensing data and GIS in making a granular site suitability assessment for solar PV projects in the province of Tarlac and perform cost-benefit analysis of land conversion by considering both the economic impact and environmental impact.

To be specific, the study aims to: identify, using analytic hierarchy process, suitable rice farms in Tarlac to potentially convert to solar farms; and estimate the potential energy generated, rice yield and net returns lost, reduction in carbon emissions and potential net income from the conversion of rice farms to a solar farm.

\subsection{Scope and Limitations}

The study area is in Tarlac that is plain on the eastern side while hilly to mountainous on the western side. One of Tarlac's prime agricultural products is rice. Tarlac also has one of the largest solar projects in the country, at $150 \mathrm{MW}$, that could give support to the Luzon grid and would even cater to those outside the province (Investment Promotion Office Department of Energy, 2020). Figure 1 shows the DEM of Tarlac Province.

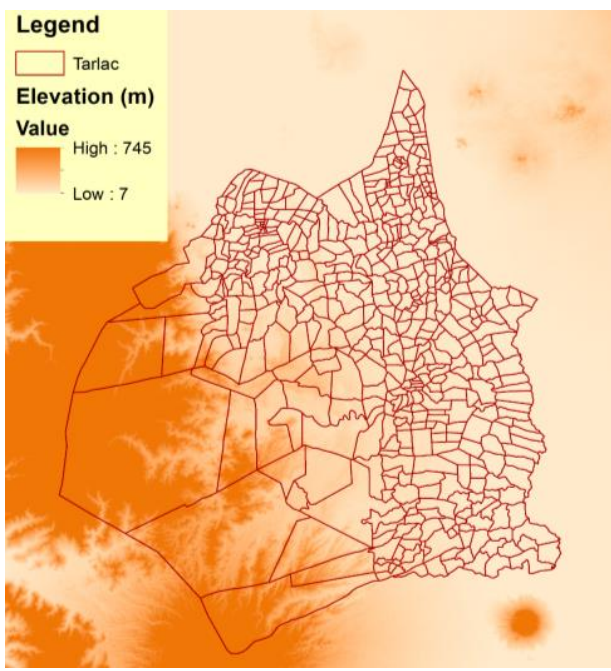

Figure 1. Digital Elevation Model of Tarlac Province from SRTM DEM (30m)

Before an agricultural land can be converted to other uses, land use is identified and its conversion to other use depends solely on the landowner. Alienable and disposable lands should be reclassified (Commonwealth Act No 141). Irrigation systems and prime rice lands were also highly restricted to be converted into other use (Inquirer, 2021).

For this study, crop lands were considered as convertible, although prime rice lands were included. Only a few factors were considered in criteria decision making, namely the methods under Analytic Hierarchy Process, as other factors would need subjective decision making from experts on the field itself which were not obtained due to the current restrictions brought by the ongoing pandemic.

For the cost-benefit analysis, only the potential net profit from solar farms, reduction in carbon emissions, and energy generated were the benefits that were considered. Meanwhile, rice yield loss due to the conversion and potential net profit from the rice field are considered for the cost. We acknowledge that there are other factors that can be considered including impacts on employment, environment (e.g., surrounding landscape and wildlife), and farmgate price of rice. The said factors were not considered in this study.

\section{LITERATURE REVIEW}

\subsection{Remote Sensing in Solar Farm Suitability Analysis}

The study of Kaya, et.al (2019) generated built-up areas using the Built-Up Index (BI) (Eq. (1)) using image Bands B4 (Red), B8 (NIR) and B11 (SWIR1). BI was used to extract built-up areas and to eliminate vegetation areas.

$$
B I=\frac{B 11-B 8}{B 11+B 8}-\frac{B 8-B 4}{B 8+B 4}=N D B I-N D V I
$$

where: $\quad B I=$ build-up index

NDBI $=$ Normalized Difference Built-Up Index NDVI $=$ Normalized Difference Vegetation Index

BI Values of 0.100-0.300 are considered as built-up areas, while those values that are not under this range are classified as barren, water, vegetation, or other land uses.

For rice values, the study of Ramadhiyanti (2019) shows the Normalized Difference Vegetation Index (NDVI) (Eq. (2)) to generate and classify different rice densities and such values are shown in Table 1.

$$
N D V I=\frac{B 8-B 4}{B 8+B 4}
$$

The slope was generated from the SRTM DEM and QGIS' slope raster analysis was used. The aspect was also generated from the DEM, using the Aspect Raster Analysis module from QGIS. The value's unit was in degrees, 0 degrees based on the east.

\begin{tabular}{|l|l|l|l|}
\hline $\begin{array}{l}\text { NDVI } \\
\text { Values }\end{array}$ & $\begin{array}{l}\text { Vegetation } \\
\text { Density }\end{array}$ & $\begin{array}{l}\text { Ages of } \\
\text { Rice Plant } \\
\text { (week) }\end{array}$ & $\begin{array}{l}\text { Ages of } \\
\text { Rice Plant } \\
\text { (days) }\end{array}$ \\
\hline
\end{tabular}




\begin{tabular}{|l|l|l|l|}
\hline$<0.170$ & $\begin{array}{l}\text { Non } \\
\text { vegetation/ } \\
\text { water }\end{array}$ & $<3$ & $<20$ \\
\hline $0.170-0.310$ & Very low & $3 \leq 4$ & $20-30$ \\
\hline $0.310-0.450$ & Low & $4-6$ & $30-40$ \\
\hline $0.450-0.520$ & Medium & $6-8$ & $40-60$ \\
\hline $0.520-0.884$ & High & $8-13$ & $60-90$ \\
\hline
\end{tabular}

Table 1. Rice Field Extraction Using NDVI

\subsection{GIS in Solar Farm Suitability}

The buffers from the built-up areas, roads, and grid line were assumed and given equal weights that would equal to $100 \%$. The slope, aspect, and possible farmland areas were then added as constraints to produce the final suitability map. To obtain the rice yield, the seed rate is assigned for different rice densities. The seed rate is the amount of seeds required to grow crops. Actual seed rate needs to have on-field data (IRRI, 2021).

\subsection{Importance of Criteria}

Criteria was based on Taweekun's (2018) study for solar site suitability. In terms of slope, relatively flat areas are more favored as the earth's gradient affects receiving radiation from the sun and for the solar panel to be more stable. This is to prevent economic factors such as construction and transportation costs to make a slope more suitable on steeper areas. GHI is also received by horizontal surfaces on the ground. For aspect, areas on the northern hemisphere must have their solar panels facing south as this will let solar panels receive direct sunlight throughout the day time and use this energy later on especially when electricity at night time is needed. Solar panels, most particularly in the southwest, will gather energy from the setting sun. From this, areas facing north (of 0-179.99 degrees) are not suitable for solar farm placement. Over time, towns will expand and shadows from large buildings would affect the performance of solar farms and solar PV efficiency drops, therefore farther distances from built-up areas are favored. Farther distances are preferred to avoid inconvenience to human activity. For the grid, nearness to the grid determines economic viability of energy projects. Farther distance may result in power line loss. For roads, farther distances from them may generate higher construction and transportation costs, therefore roads closer to the solar farms are favored. Prime agricultural lands cannot be converted to something else and these lands should be conserved. These lands are then considered as constraints and the rice in this area will not be counted to the cost and benefit analysis.

In the Philippine setting, a study by Sola, et. al (2019) showed a suitability assessment for solar powered farms was done in Pampanga, and it is said that the Philippines, being a tropical country, receives high amounts of solar radiation.
In this study Pampanga is said to have moderate to high suitability for solar powered farms. The study also included in one of their criteria the susceptibility of Pampanga to earthquakes, water bodies, flood susceptibility, and the protected areas. Areas prone to heavy landslides and earthquake damages were taken into account. Compared to studies from other countries, earthquakes and flood susceptibility should be noted as frequently the Philippines experiences natural disasters.

\subsection{Cost-Benefit Analysis}

Cost-Benefit Analysis was used in an analysis of the viability of the province of Bohol achieving a $35 \%$ or greater domestic renewable energy portfolio was done by Pojadas, et. al (2021).

\subsection{Profit from Solar Farms}

An analysis on the comparative attractiveness of renewable energy sources against coal for electricity generation in the Philippines was done by Agaton (2018). In the analysis to estimate the gross profit from a solar farm they used the domestic electricity price in the Philippines which is Php 9045.05 per MWh.

\subsection{Levelized Cost of Electricity}

The operation and maintenance costs, and the fuel costs were used in a study by Chung Sing Lai, et. al (2017) where they proposed an LCOE approach for electricity storage. The LCOE used by Pojadas, et. al, in their study was used to generate the supply curves with which the energy portfolio analysis was based.

\subsection{Estimation of Energy Generated}

The estimation of energy generated, in the study by Pojadas, et. al, had used values not specific to Bohol but represented the entirety of the Philippines. This is because of data limitations. The values they used for estimation are the capacity factor $(\mathrm{CF})$, which is the ratio of the maximum output and the actual output over a period of time (Understanding Energy Capacity and Capacity Factor, 2021), was estimated to be $14.6 \%$ and was extracted using the only weather station data available for the Philippines which is located in Manila. The power density (PD) from their study was averaged from 30 existing solar farms in the country and was found to be $100 \mathrm{MW} / \mathrm{km} 2$.

\subsection{Carbon Emission Reduction}

In estimating the carbon emissions potentially reduced by the construction of a solar farm Pojadas et al. had assumed that every MWh of electricity from the solar farm would replace each MWh generated by a coal power plant. They had based their estimates on the median lifecycle greenhouse gas emission found in the 2012 report of the Intergovernmental Panel on Climate Change. 


\subsection{Rice Yield \& Income Estimation}

Rice yield is a statistic recorded by the Department of Agriculture through the Philippine Rice Information System (PRiSM, 2019). PRiSM provides biannual rice yield estimates at a provincial level in tons per hectare. Average production cost and returns are statistics recorded by the Philippine Statistics Authority. Estimations are done at a regional level and are done per season. The two seasons are dry and wet. Net returns are calculated by subtracting the total costs to the gross returns. The gross returns are the product of the total production and the farmgate price.

\section{METHODOLOGY}

The processes in this study mainly involve data gathering, remote sensing techniques, and GIS techniques to get the needed rice farm areas. The Global Horizontal Irradiance (GHI) was calculated by using the Area Solar Radiation module in ArcGIS. The calculation date was set to 2019 to be able to compare it with the GHI data from SolarGIS. The unit used is $\mathrm{kWh} / \mathrm{m} 2 / y e a r$. Using the areas computed to calculate the costs which include the rice yield and the net income from the rice yield, and then calculating the benefits which were the net income from the solar farm, the electricity produced and the carbon emission reduced.

\subsubsection{Satellite Image}

The satellite images used for processing the required data were Sentinel $2 \mathrm{~A}$ tiles taken from the Copernicus website. The tiles are merged and shown in Figure 2.

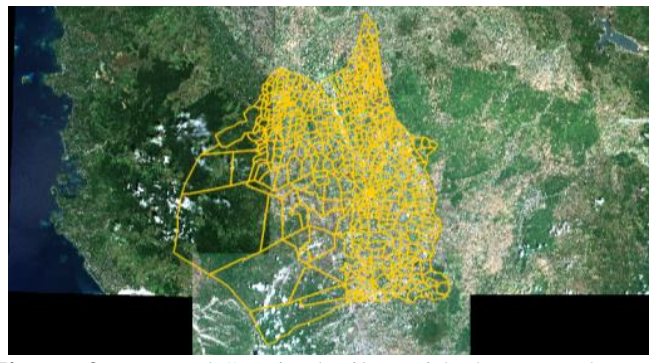

Figure 2. Merged Sentinel Tiles with the Boundary of Tarlac (in yellow)

\subsubsection{Statistical Data}

Table 2 shows the statistical data obtained for other factors and constraints. The original resolution of these data were resampled to $30 \mathrm{~m}$ to accommodate the resolution of the SRTM DEM. All data were reprojected to WGS 1984 UTM Zone 51. Factors, constraints, and suitability levels are identified for their weightage for multi-criteria analysis.

\subsection{Data}

\begin{tabular}{|c|c|c|c|c|}
\hline & Factor & Source & Suitability & Overall Weightage \\
\hline Accessibility & Built-up Area & $\mathrm{BI}$ from Sentinel 2A & $\begin{array}{l}\text { Not Suitable: }<1 \mathrm{~km} \\
\text { Low: } 1-1.5 \mathrm{~km} \\
\text { Moderate: } 1.5-2 \mathrm{~km} \\
\text { High: }>2 \mathrm{~km}\end{array}$ & 0.167 \\
\hline Accessibility & $\begin{array}{l}\text { Road } \\
\text { Network }\end{array}$ & $\begin{array}{l}\text { Humanitarian Data } \\
\text { Exchange (2018) }\end{array}$ & $\begin{array}{c}\text { Not Suitable: }<0.5 \mathrm{~km},>10 \mathrm{~km} \\
\text { Low: } 5-10 \mathrm{~km} \\
\text { Moderate: } 2-5 \mathrm{~km} \\
\text { High: } 0.5-2 \mathrm{~km}\end{array}$ & 0.167 \\
\hline Accessibility & Grid & $\begin{array}{l}\text { Humanitarian Data } \\
\text { Exchange (2018) }\end{array}$ & $\begin{array}{l}\text { Low: } 5-10 \mathrm{~km} \\
\text { Moderate: } 1-5 \mathrm{~km} \\
\text { High: } 0-1 \mathrm{~km}\end{array}$ & 0.167 \\
\hline Main Resource & $\begin{array}{l}\text { Solar Electric } \\
\text { Potential (GHI) }\end{array}$ & $\begin{array}{l}\text { Remote Sensing } \\
\text { Technique from DEM }\end{array}$ & $\begin{array}{c}\text { Low: }<1400 \mathrm{kWh} / \mathrm{m} 2 \\
\text { Moderate: } 1400-1500 \mathrm{kWh} / \mathrm{m} 2 \\
\text { High: }>1500 \mathrm{kWh} / \mathrm{m} 2\end{array}$ & 0.5 \\
\hline Constraint & Slope & SRTM DEM & Must be $<10$ degrees & \multirow[t]{3}{*}{$\begin{array}{l}\text { Omits non-suitable } \\
\text { areas }\end{array}$} \\
\hline Constraint & Aspect & SRTM DEM & $\begin{array}{c}\text { Must be facing south, southeast, or } \\
\text { southwest }\end{array}$ & \\
\hline Constraint & $\begin{array}{l}\text { Prime Rice Areas and } \\
\text { Arable Croplands }\end{array}$ & $\begin{array}{l}\text { Humanitarian Data } \\
\text { Exchange (2018) }\end{array}$ & $\begin{array}{l}\text { Must be arable cropland, and not a } \\
\text { prime rice area }\end{array}$ & \\
\hline
\end{tabular}

Table 2. Factors and Constraints with their Weightage 
The suitability scores are as follows: high suitability has a value of $2-3$, moderate suitability has a value of $1-2$, low suitability has a value of $0-1$, while those under not suitable have no value, or 0 .

\subsection{Calculating Pertinent Values}

\subsubsection{Solar Farm Estimated Electricity Generated}

To estimate the electricity generated (E) we used the formula used by Pojadas et al. For our study we compared annual values so time is set to the number of hours in a year, 8760 hours. These values were multiplied to the area to estimate the electricity generated.

\subsubsection{Solar Farm Net Profit}

To estimate the net profit $\left(\mathrm{NP}_{\text {solar }}\right)$ from the solar farm the gross profit (GP) was first calculated using the price of electricity used by Agaton (2018), Php 9045.05 per MWh. After which the Site-LCOE used by Pojadas (2021) was calculated and subtracted from the gross profit to get the estimated net profit per area. The Site-LCOE was calculated with Unit Capital Expenditure (UCE) at 56,707,554 in Php/MW, the Capital Recovery Factor (CRF), the fixed cost for operation and maintenance at 673,240 in Php/MWh-year (FCOM) and the capacity factor (CF) at $14 \%$. The CRF was calculated with the weighted average cost of capital (i) at $4.25 \%$ and farm lifespan $(\mathrm{N})$ at 25 years.

\subsubsection{Amount of carbon emissions reduced}

The amount of carbon emissions reduced is estimated with the same method as used by Pojadas (2021), using the rate of greenhouse gas emissions per KWh for Solar PVs and Coal. The amount of greenhouse gas emissions produced from power generation using coal is subtracted from the amount produced from Solar PVs then multiplied by the amount of energy produced. Here we used the median rate for solar pv and coal which are $46 \mathrm{~g} \mathrm{CO}^{2} \mathrm{eq} / \mathrm{kWh}$ and $1001 \mathrm{~g}$ $\mathrm{CO}^{2} \mathrm{eq} / \mathrm{kWh}$ respectively (Ottmar, 2021).

\subsubsection{Rice Farm Yield with statistical data}

Rice farm yield was also estimated using the statistical data from the Philippine Rice Information System (PRiSM). PRiSM reports an estimate of $426376.8278 \mathrm{~kg} / \mathrm{km}^{2}$ of palay from Tarlac for the first semester of 2020 and 433913.8643 $\mathrm{kg} / \mathrm{km}^{2}$ for the second semester. To estimate the rice yield, these two values were averaged, which is $430,145.3461$ $\mathrm{kg} / \mathrm{km}^{2}$ and multiplied to the area of each lot.

\subsubsection{Rice Farm Net Profit}

The net return of a rice farm was approximated using linear regression with historical data from the Philippines Statistics Authority on net returns of palay from 2010 to 2018 . The value produced is $9,931,928.89 \mathrm{php} / \mathrm{km}^{2}$-year.

\section{RESULTS AND DISCUSSION}

\subsection{Suitable Areas for Solar Farms}

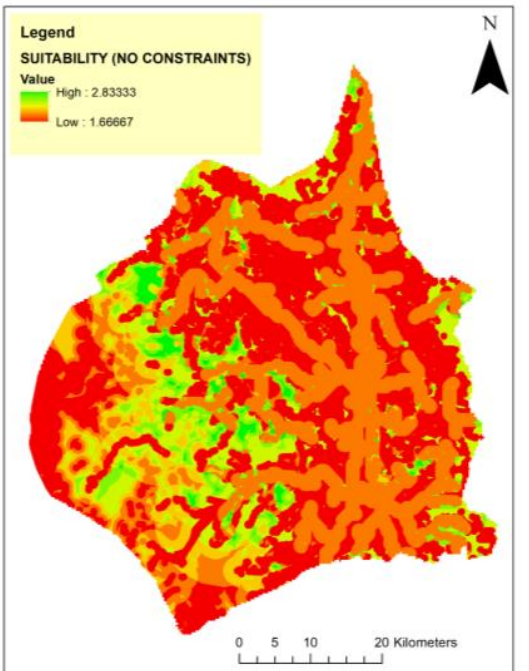

Figure 3. Suitability Map of Tarlac (no constraints)

By performing the criteria analysis, Figure 3 shows the suitability map of Tarlac. With the added constraints, Figure 4 then shows the produced final suitability map of solar farms in Tarlac based on the raster calculations.

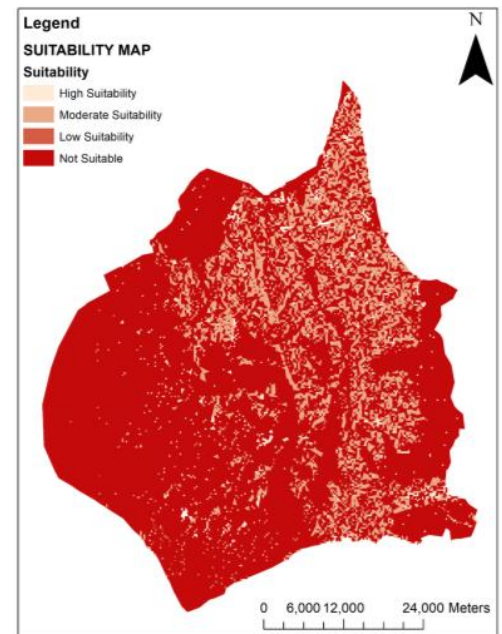

Figure 4. Final Suitability Map of Solar Farms in Tarlac

There are existing and upcoming solar farms or projects in Tarlac. These were compared with the generated suitability map for solar farms to see the suitability of these solar projects and to plan a placement for the upcoming solar farm projects. These projects are shown in Figure 5. 


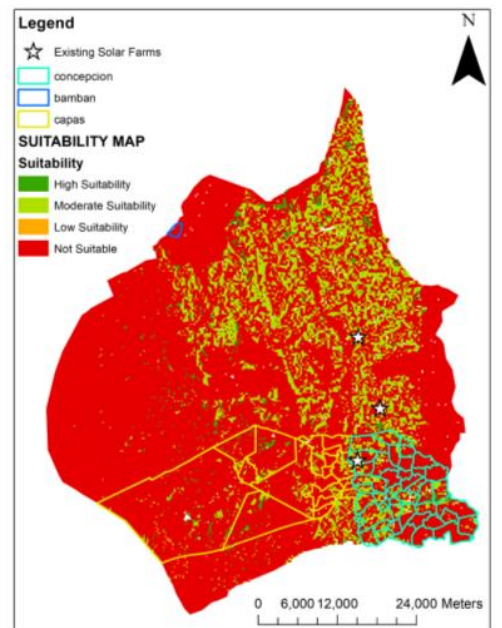

Figure 5. Areas of Solar Projects in Tarlac

\subsection{Calculated Rice Yield}

Figure 6 and Figure 7 are the maps generated to identify the convertible rice fields that fall under moderate solar farm suitability and high solar farm suitability.

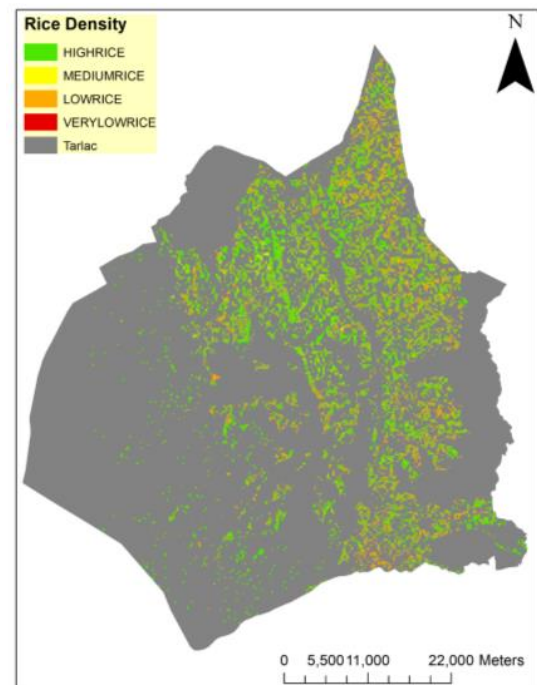

Figure 6. Convertible Rice Fields on Suitable Solar Farm Areas

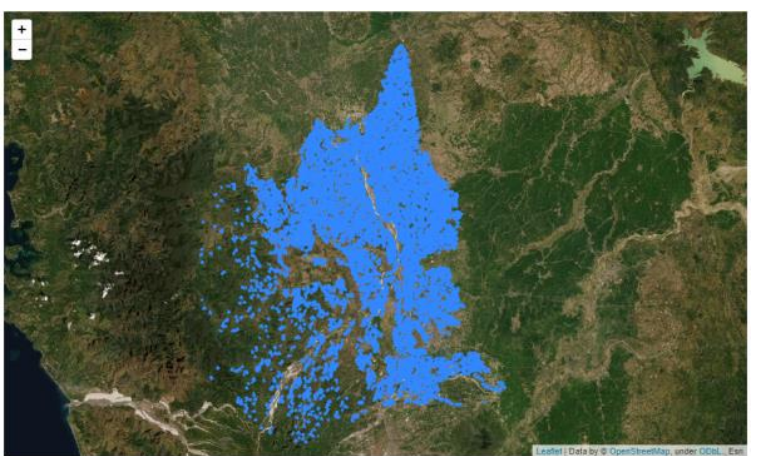

Figure 7. Final Suitable Areas in Tarlac

\subsection{Estimated yield reduction}

As shown in Figure 8 to 12, it was calculated that the yield of the region would have decreased by $8.12 \%$, around 25,393 metric tons of rice if the rice fields were converted.
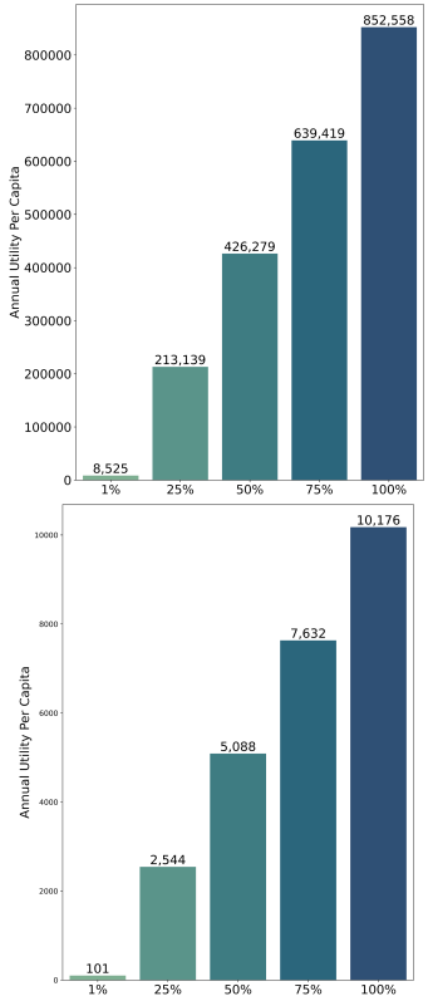

Figure 8 and 9. Annual utility capita affected with different percentages of conversion; rice yield based on seed density (above); rice yield based on statistical data (below)

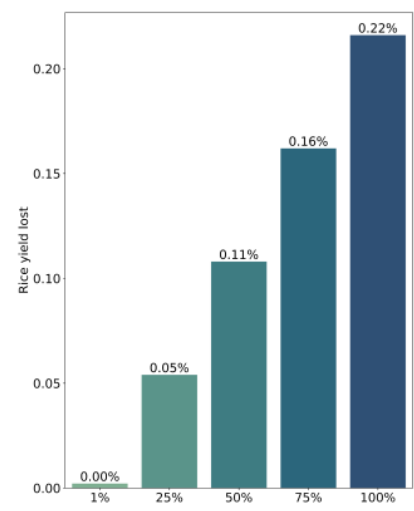

Figure 10. Tarlac annual rice yield production lost with different percentages of conversion; rice yield based on seed density 


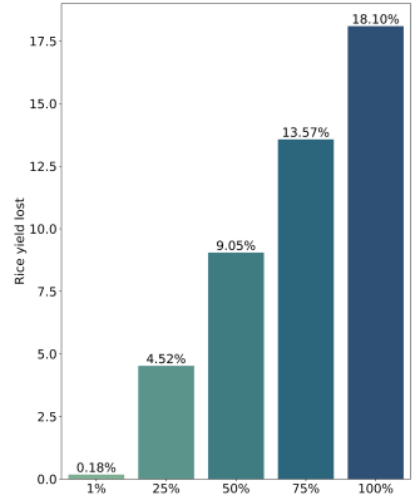

Figure 11. Tarlac annual rice yield production lost with different percentages of conversion; rice yield based on statistical data

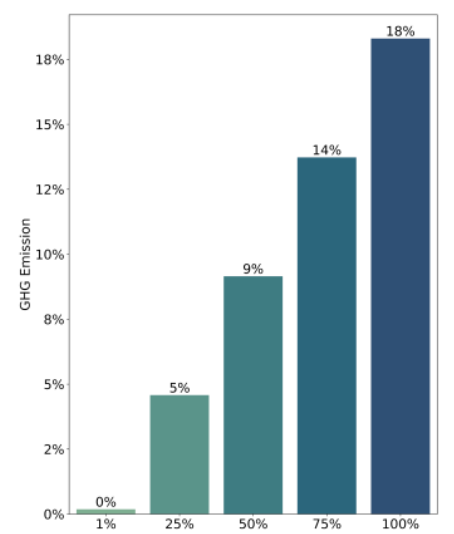

Figure 12. Estimated reduction of national carbon emissions with different percentages of conversion

\subsection{Economic Impact}

Figure 13 and Figure 14 shows the economic impact of this suitability assessment. From an economic perspective, the range of the means of the net profits for solar farms look promising as the minimum matches the approximate yearly profit from the rice. The upper bound reaches up to 40 times higher than the net profit from rice.

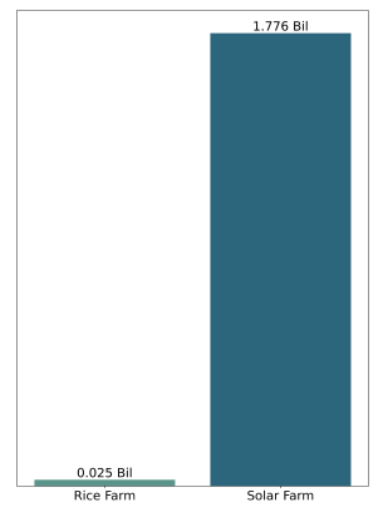

Figure 13. Estimated annual net profit (Php/yr) comparison of a rice farm and a solar farm

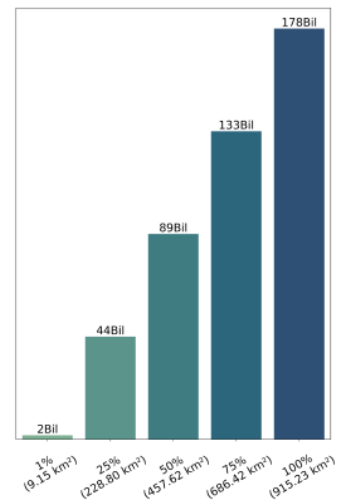

Figure 14. Estimated annual net profit (Php/yr) comparison of just solar farms with different percentages of conversion

\section{CONCLUSION}

Based on the processed suitability map and on cost-benefit analysis, this study showed the promising economic value of solar farms in the province of Tarlac with sufficient installation capacity to be eligible for FiT allowance. At worst it will match the estimated net profit of rice farm areas selected at $122,877,479 \mathrm{php}$ with $132,535,964 \mathrm{php}$, but at best estimated net profits could go as high as 5,027,990,357 php.

This study has also emphasized the environmental benefit of converting agricultural areas to solar farms by lowering the province's dependence on non-renewable sources of energy, particularly coal in this case. The approximated reduction in emissions was $33.7 \%$ of the emissions of the whole province.

It was also notable how much of the national rice supply could be affected as rice supply for more than 200,000 people for a year would have to be forgone. But even with that concern, it is recommended that Tarlac convert rice farms that are in highly suitable areas to solar farms since these areas do not take a significant amount of rice yield away from the region.

It is recommended that more advanced techniques, such as instance segmentation to outline the rice fields, so that the areas of interest would be more well defined. The results may also benefit from a better estimation of the power grids in the area for site-suitability analysis. These improvements could make the final suitable areas more accurate.

\section{REFERENCES}

About Tarlac Province, 2019. Island Properties. Retrieved on January 4, 2021, from: https://www.islandsproperties.com/places/tarlac.htm

Agaton, C.B, 2018. Use coal or invest in renewables: a real options analysis of energy investments in the Philippines. Renewables 5, 1. doi.org/10.1186/s40807-018-0047-2

Climate Action, 2017. The Philippines pursues renewable energy expansion. Retrieved January 06, 2021, from 
https://www.climateaction.org/news/the_philippines_pursu es_renewable_energy_expansion

Commonwealth Act No. 141. Public Land Act, 1936. Retrieved October 18, 2021 from media.dar.gov.ph/source/2018/06/29/commonwealth-actno-141.pdf

Converting agricultural land for development use, 2021. business.inquirer.net/318173/converting-agricultural-landfor-development-use

Cruz, E. D., et al; Petty, M., 2017. Philippines seeks investors to power growth, extra 7,000 MW needed. Reuters. Retrieved January 06, 2021, from reuters.com/article/ukphilippines-energy/philippines-seeks-investors-to-powergrowth-extra-7000-mw-needed-idUKKBN1661BF.

Deutsche Gesellschaft für Internationale Zusammenarbeit (GIZ) GmbH, 2013. IT'S MORE SUN IN THE PHILIPPINES: Facts and Figures on Solar Energy in the Philippines Project Development Programme (PDP) Southeast-Asia.

doe.gov.ph/sites/default/files/pdf/netmeter/policy-brief-itsmore-sun-in-the-philippines-V3.pdf

Edenhofer, Ottmar, 2021. Special Report on Renewable Energy Sources and Climate Change Mitigation, Technical Support Unit Working Group III Potsdam Institute for Climate Impact Research. Retrieved March 7, 2021 from archive.ipcc.ch/pdf/special-

reports/srren/SRREN_FD_SPM_final.pdf

Ettehadi, P., Kaya S., Sertel E., Alganci U., 2019. Separating Built-Up Areas from Bare Land in Mediterranean Cities Using Sentinel-2A Imagery.: Remote Sens. 2019, 11(3), 345. doi.org/10.3390/rs11030345

Ali, S., Taweekun, J., Techato, K., Waewsak, J., Gyawali, S., 2018. GIS based site suitability assessment for wind and solar farms in Songkhla, Thailand. doi.org/10.1016/j.renene.2018.09.035

France-Presse, A. 2011,. Philippines sets 50\% renewables target by 2030. Retrieved January 06, 2021, from https://business.inquirer.net/4182/philippines-sets-50renewables-target-by-2030

Guno, C. Agaton, C., Villanueva, R., and Villanueva, R., 2021 Optimal Investment Strategy for Solar PV Integration in Residential Buildings: A Case Study in The Philippines, International Journal of Renewable Energy Development, vol. 10, no. 1, pp. 79-89. doi.org/10.14710/ijred.2021.32657

Gürtürk, M., 2019. Economic feasibility of solar power plants based on PV module with levelized cost analysis. Energy. doi:10.1016/j.energy.2019.01.090

International Rice Research Institute.. Definition of Seed Rate, Formula, Objectives, and Factors, 2019. International Rice Research Institute. knowledgebank.irri.org/decisiontools/rice-doctor/rice-doctor-fact-sheets/item/seed-high-rate
Investment Promotion Office Department of Energy , 2020. Energy Projects in Region III, Energy Investment Briefing, Public Consultation on the LGU Energy Code, and EVOSS IEC. doe.gov.ph/sites/default/files/pdf/e_ipo/03_032020_energy_projects_for_region_III.pdf

Lai, C.S., McCulloch, M.D., 2017.. Levelized cost of electricity for solar photovoltaic and electrical energy storage. doi.org/10.1016/j.apenergy.2016.12.153

Mondal, M.A.H., Denich, M, 2010. Assessment of renewable energy resources potential for electricity generation in Bangladesh. Renew Sustain Energy Rev, 14 pp. 2401-2413. doi.org/10.1016/j.rser.2010.05.006

Pojadas, D.J., Abundo, M.L.S., 2021. Spatio-temporal assessment and economic analysis of a grid-connected island province toward a $35 \%$ or greater domestic renewable energy portfolio: a case in Bohol, Philippines. Int J Energy Environ Eng. doi.org/10.1007/s40095-020-00369-7

PRiSM, 2019. Philippine Rice Information System. Retrieved January 06, 2021, from /prism.philrice.gov.ph/aboutus/\&sa=D\&source=editors\&us $\mathrm{t}=1625013823922000 \& u s g=A O v V a w 1$ lzZO2RjClHRo9Cf nXkOj1

Ramadhiyanti, M. S., M. D.M. Manessa, and Y. Ristya, 2019 .The Spatial Pattern of Rice Productivity Using Sentinel-2A Image in Cariu and Tanjungsari District, Bogor Regency. 10.18502/keg.v4i3.5883

Rome, R., 2018. How Much Do You Really Save with Solar in the Philippines. Retrieved on January 4, 2021, from https://solaric.com.ph/blog/solar-philippines-save/

Sola, E. Pintor, B.H.S., Teves, J.G., Inocencio, L.C.V. and Ang, M.R.C.O, 2019. Selection of Optimum Sites for Solar Energy Farms using a GIS-Based Solar Radiation Model and Site Suitability Analysis. 10.1.1.741.8366

Understanding Energy Capacity and Capacity Factor (2021). Retrieved January 06, 2021, from nmppenergy.org/feature/capacity_factor 